\title{
Sublingual misoprostol versus dinoprostone gel in labour induction
}

\author{
Juveria Jahangir, Fatima Zahra Shaik Mohd
}

Correspondence: Dr.Fatima Zahra Shaik Mohd, Associate Professor in the Department of Obstetrics and Gynaecology, Dr.VRK Women Medical College, Aziz Nagar, Hyderabad, Telangana; Email - fatimazehwa@gmail.com

Distributed under Attribution-Non Commercial - Share Alike 4.0 International (CC BY-NC-SA 4.0)

\begin{abstract}
Objective: This study was carried out to compare the outcome and safety of intravaginal misoprostol (PGE1) and intra-cervical dinoprostone gel (PGE 2) in induction of labour. Methods: In this study, 100 women between 19 and 30 years of age with a single live fetus, cephalic presentation and full-term pregnancy were included for induction of labour. Fifty women received 50 micrograms of Misoprostol intravaginal (study group) and 50 women received $0.5 \mathrm{mg}$ of intracervical dinoprostone gel (control group). The comparison were made on the average time taken for the start of labour, the induction time at birth, the average duration of delivery, the need for oxytocin, the method of delivery. Results: The average time taken for the onset of labour was lower in the misoprostol group than in the dinoprostone group (40.30 min v/s 1 hour and 35 minutes). Similarly, the induction phase to the active phase ( 1 hour and $44 \mathrm{~min} \mathrm{v/s} 4$ hours and $25 \mathrm{~min}$ ) and the active phase at the time of administration to delivery ( 3 hours $00 \mathrm{~min} \mathrm{v} / \mathrm{s} 4$ hours $48 \mathrm{~min}$ ) was lower for the misoprostol group. The rate of caesarean section was lower in the misoprostol group $(6 \% \mathrm{v} / \mathrm{s} 26 \%)$. Maternal side effects were negligible in both groups and the neonatal outcome was good in both groups. The cost of induction was much lower in the misoprostol group. Conclusion: Misoprostol is a safe, effective and economical drug, suitable for the mother and the fetus for the induction of labour.
\end{abstract}

Keywords: Dinoprostone gel, induction of labour, misoprostol.

Induction of labour is defined as the process of artificially stimulating the uterus to start labour ${ }^{1}$. In about 5 to $25 \%$ of pregnancies, there comes a time when the fetus and / or the mother would be better if the birth is guided ${ }^{2}$. Prostaglandins alter the extracellular fundamental substance of the cervix, mature the cervix and also increase the activity of collagenase in the cervix. They also allow an increase in intracellular calcium levels, causing contraction of the myometrial muscle ${ }^{3,4}$.
Currently, there are two prostaglandin analogs available for cervical ripening: Misoprostol and Dinoprostone Gel. Misoprostol (15-deoxy-16-hydroxy-16-methyl-PGE1) was the first synthetic analog of prostaglandin available for the treatment of peptic ulcer. Impressed by his stimulating actions on the uterus, Sánchez Ramos in 1993 used it to control various obstetric conditions. Misoprostol is available in tablets of 50, 100, 200 micrograms. Dinoprostone (PGE) is a synthetic preparation of natural

Received: $23^{\text {rd }}$ September 2019. Accepted: $3^{\text {rd }}$ December 2019.

Jahangir J, Mohd FZS. Sublingual misoprostol versus dinoprostone gel in labour induction. The New Indian Journal of OBGYN. 2020; 6(2): 127-30. 
prostaglandin E2. The PGE 2 gel is available in a $2.5 \mathrm{ml}$ syringe for an intracervical application of $0.5 \mathrm{mg}$ of Dinoprostone ${ }^{5}$. This study was carried out to compare the outcome and safety of intravaginal misoprostol (PGE1) and intra-cervical dinoprostone gel (PGE 2) in induction of labour.

\section{Materials and Methods}

Randomly selected 100 women who were admitted for birth induction. Fifty women received 50 micrograms of intravaginal Misoprostol and another 50 women received $0.5 \mathrm{mg}$ intracervical dinoprostone in a gel. Misoprostol $(50 \mu \mathrm{g})$ remained in the posterior fornix after wetting. Doses were repeated in both groups every 6th hourly upto maximum of 3 doses.

Inclusion criteria: Cephalic single pregnancy, $>37$ weeks pregnancy on ultrasound.

Exclusion criteria: Multiple pregnancy, abnormal presentation, pregnancy $<37$ weeks, previously caesarean. Study group: Misoprostol for labour induction.

Control group: Patients who received dinoprostone gels for labour induction.

The patients were evaluated in an active phase with cervical dilatation of at least 3-4 cms.

When they entered in active phase of the uterine contraction, oxytocin was started. If women have not reached in active labour in 24-hours, a caesarean

Table 4: Induction delivery intervals

\begin{tabular}{llll}
\hline Categories & Misoprostol & Dinoprostone & Mean difference \\
\hline Induction to active phase & $1 \mathrm{hr} 44 \mathrm{~min}$ & $4 \mathrm{hrs} 25 \mathrm{~min}$ & $2 \mathrm{hrs} 18 \mathrm{~min}$ \\
Active phase to delivery & $3 \mathrm{hrs} 00 \mathrm{~min}$ & $4 \mathrm{hrs} 48 \mathrm{~min}$ & $1 \mathrm{hr} 6 \mathrm{~min}$ \\
Induction to delivery & $4 \mathrm{hrs} 2 \mathrm{~min}$ & $10 \mathrm{hrs} 45 \mathrm{~min}$ & $6 \mathrm{hrs} 10 \mathrm{~min}$ \\
\hline
\end{tabular}
section was performed for the failed induction. The results were expressed as a means and deviation tests and unspent tests were applied to identify the statistical significance. The qualitative variables were expressed as a percentage. The neonatal outcome was measured based on an APGAR score.

\section{Results}

Reference data for the study population included maternal age, pregnancy, and gestational age. They were

Table 1: Gestational age

\begin{tabular}{lll}
\hline Gestational age & Misoprostol & Dinoprostone gel \\
\hline $37-40 \mathrm{wks}$ & $36(72 \%)$ & $38(86 \%)$ \\
$40-42 \mathrm{wks}$ & $14(28 \%$ & $12(24 \%)$ \\
\hline
\end{tabular}

comparable in two groups. The average gestational age was identical from 37 to 42 weeks. Thirty six number of women $(72 \%)$ in the main group and $86 \%$ in the control group were pregnant between 37 and 40 weeks, as shown in table 1.

The average time spent at the onset of labor was significantly lower $(\mathrm{P}=0.00039)$ in the misoprostol group Table 2: Induction indications

\begin{tabular}{lll}
\hline Indications & Misoprostol & Dinoprostone \\
\hline Postdated pregnancy & $16(32 \%$ & $18(36 \%)$ \\
IUGR & $14(28 \%)$ & $11(22 \%)$ \\
PIH/Pre-eclampsia & $20(40 \%)$ & $21(42 \%)$ \\
\hline
\end{tabular}

(42.30 min compared to 1 hour and 35 minutes), as shown
Table 3: Mean time onset of labour

\begin{tabular}{llll}
\hline Categories & Misoprostol & Dinoprostone & Mean difference \\
\hline In all patients & $42.30 \mathrm{~min}$ & $1 \mathrm{hr} 35 \mathrm{~min}$ & $55.80 \mathrm{~min}$ \\
In Primigravida & $48.40 \mathrm{~min}$ & 1 hour $30 \mathrm{~min}$ & $43.40 \mathrm{~min}$ \\
In Multigravida & $40.25 \mathrm{~min}$ & 1 hour $25 \mathrm{~min}$ & $50.30 \mathrm{~min}$ \\
\hline
\end{tabular}

in table 3. Therefore, misoprostol causes premature delivery and, therefore, earlier delivery than dinoprostone.

In the Misoprostol group, the time required for induction of the active phase (1 hour 44 minutes compared to 4 hours 25 minutes) was lower, statistically significant at $\mathrm{P}=0.004$. Similarly, the active phase in the administrative interval ( 3 hours 00 minutes vs 4 hours 48 minutes) was also lower and was statistically significant with $\mathrm{P}=0.08$ (Table 4). There was no need of augmentation of labour with oxytocin in any case in the misoprostol group, but in $3(6 \%)$ patient of dinoprostone group, augmentation was needed.

Only one patient in the study group had an induction failure, and seven patients in the control group had an induction failure. The main indicator for the caesarean section of the control group was the lack of induction, as shown in table 5 . In the study group, a caesarean section was predominantly for the meconium liquor, which was the second key indicator for the caesarean part of the control group.

Although fever with chills, hyperstimulation (hypersystole and tachycardia) and more colored liquor in the misoprostol group were in complications than in dinoprostone group, no other significant side effects were 
Table 5: Mode of delivery and indications for caesarean section.




allowed to be given for childbirth or to terminate a pregnancy. Despite this, the College of American Obstetricians and Gynaecologists (2000) has confirmed its urgent need to use this drug to ensure safety and efficacy $^{13}$.

Birth weight was similar in both groups. An Apgar score of $<7$ was seen after 1 minute in 3 cases from the dinoprostone group, and two of them were to be admitted to the intensive care unit. The total average cost of induction in the misoprostol group was significantly lower.

\section{Conclusion}

The results of our studies showed that misoprostol efficacy is better than dinoprostone jelly. It takes short duration from induction to delivery periods. The need of augmentation with oxytocin was lower in misoprostol and the number of vaginal births was higher in misoprostol than dinoprostone. Misoprostol is a safe, effective and economical drug, suitable for the mother and the fetus for the induction of labor.

\section{Conflict of interest: None. Disclaimer: Nil. References}

1. WHO. Managing complication in pregnancy and childbirth: a guide for midwives and doctors. Geneva: World Health Organization; 2000. available at: http:// www.who.int/

reproductivehealth/publications/maternal_perinatal_heal th/9241545879/en/index.html

2. Beischer NA, Mackay EV, Colditz PB. Obstetrics and the Newborn: An Illustrated Textbook. 3rd revised edition. Kent: Bailliere Tindall; 1997.

3. Witter FR. Prostaglandin E2 preparations for preinduction cervical ripening. Clin Obstet Gynecol. 2000; 43: 469-74

4. Arias F. Pharmacology of oxytocin and prostaglandins. Clin Obstet Gynecol. 2000; 43: 45568.

5. Cunningham FG, Leveno KJ, Bloom SL, Spong CY, Dashe JS, Hoffman BL, editors. Williams Obstetrics. 23th Edition. New York: McGraw-Hill Education/Medical; 2010. pp 502
6. Latika S, Biswajit C. Comparison of prostaglandin E1 (misoprostol) with prostaglandin E2 (dinoprostone) for the induction of labor. J Obstet Gynecology India. 2004; 54 (2): $139-42$

7. Murthy BK, Arkalgud MS. Misoprostol alone compared to a mixture of dinoprostone and oxytocin for induction labor. J Obstet Gynec India. 2006; 56 (5): $413-6$

8. Agarwal N, Gupta A, Kriplani A, Bhatla N, Parul N. Six hourly vaginal misoprostol versus intracervical dinoprostone for cervical ripening and labor induction. Journal of Obstetrics and Gynaecology Research. 2003; 29(3):147-51.

9. Harry D, Figueroa R, Kalisz RB. A randomized control study of vaginal misoprostol inserts compared to vaginal dinoprostone inserts for labor induction. Journal of Maternal and Fetal and Newborn Medicine. 2003; 13 (4): $254-9$

10. Calder AA, Lafney AD, Weir SJ, Barber JV. Induction of labor in unapproved and multiple women: judge in the UK, multicellular, open labeling of their inherent implant compared to dinoprostone. BJOG. 2008; 115 (10): 1279-88.

11. Ozkan S, Kaliskan E, Doger E, Usesa I, Ozeren S, Vural B. Comparative safety and efficacy of vaginal misoprostol in relation to dinoprostone. Enter vaginal on labor induction on time: a randomized trial. Gynecological and obstetric archives. 2009; 280 (1): 19-24

12. Niger R, Greaves PK. Comparison of misoprostol and dinoprostone of the cervix by maturity of the cervix and induction of labor. 2001; 94 (1): 25-7

13. Cheng SY, Ming H, Lee JC. Oral administration compared to vaginal misoprostol for induction of labor: a randomized control test. 2008; 111: 119 - 25 .

\footnotetext{
Juveria Jahangir ${ }^{1}$, Fatima Zahra Shaik Mohd ${ }^{2}$

${ }^{1}$ Assistant Professor in the Department of Obstetrics and Gynaecology Deccan Collage Of Medical Sciences, DMRL X Road, KanchanBagh, Hyderabad, Telangana;

${ }^{2}$ Associate Professor in the Department of Obstetrics and Gynaecology Dr.VRK Women Medical College, Aziz Nagar, Hyderabad, Telangana.
} 